\title{
EFFECTS OF MIX PROPORTION ON ELECTRICAL RESISTIVITY OF CONCRETE WITH FLY ASH
}

\author{
Su Wai Hnin ${ }^{1}$, Pakawat Sancharoen ${ }^{2}$, and Somnuk Tangtermsirikul ${ }^{3}$ \\ ${ }^{1}$ School of Civil Engineering and Technology, Sirindhorn International Institute of Technology, Thammasat \\ University, Bangkok, Thailand, e-mail: ms.suwaihnin@gmail.com \\ ${ }^{2}$ Construction and Maintenance Technology Research Center, Sirindhorn International Institute of \\ Technology, Thammasat University, Bangkok, Thailand, e-mail: pakawat@siit.tu.ac.th \\ ${ }^{3}$ School of Civil Engineering and Technology, Sirindhorn International Institute of Technology, Thammasat \\ University, Bangkok, Thailand, e-mail: somnuk@siit.tu.ac.th
}

Received Date: October 10, 2016

\begin{abstract}
The aim of this paper is to investigate the effects of mix proportion on electrical resistivity of concrete with fly ash. The electrical resistivity of concrete is measured by using four Wenner probes. The varied parameters in this study were water/binder ratio, fly ash content, and paste content. Electrical resistivity of water-saturated concrete at several different ages was studied and compared with compressive strength and rapid chloride penetration. Based on experimental results, a good relationship was obtained between results of compressive strength and rapid chloride penetration with electrical resistivity of concrete. The results of this study can be applied further to predict electrical resistivity of concrete when mix proportions are provided. According to the results, lower water/binder ratio concrete had higher resistivity than those with higher water/binder ratios. When cement was replaced at $40 \%$ by fly ash, electrical resistivity increased four times when compared to that of OPC concrete.
\end{abstract}

Keywords: Compressive strength, Electrical resistivity, Mix proportion, Rapid chloride penetration

\section{Introduction}

Reinforcing steel corrosion is mainly caused by depassivation of steel. It occurs due to $\mathrm{pH}$ reduction of pore solution, due to carbonation or by ingress of chloride ions. Reinforcing steel corrosion is an electrochemical process. Thus, electrochemical properties of concrete, such as electrical resistivity, are important factors controlling this corrosion process. Therefore, concrete resistivity can be used as a tool to determine the severity of corrosion in reinforced concrete structures. Only a few research papers have been done to investigate this problem. Surface concrete resistivity is used to evaluate rate at which corrosion occurs in concrete and to assess capacity of concrete to allow corrosion [1, 2]. Normally, concrete electrical resistivity ranges from 1 to $10,000 \mathrm{k} \Omega-\mathrm{cm}$, depending on the moisture content of the concrete, temperature, and concrete quality (composition, cement type, etc.) [3, 4]. Higher resistivity causes lower corrosion current travelling between anodic and cathodic areas in reinforced concrete [5]. Table 1 shows the comparison of electrical resistivity and corrosion rate of concrete.

Improvement of chloride penetration resistance of fly ash concrete due to pore refinement and increased chloride binding capacity are well studied and widely used in Thailand. However, when RC structure was corroded, application of cathodic protection was less effective in case of fly ash concrete due to its higher electrical resistivity [6]. In order to effectively design and install cathodic protection system, effect of fly ash on resistivity of concrete is needed to be studied. Electrical resistivity test is a fast and simple test that is used 
to evaluate the resistance of concrete against to enter of ionic species. In concrete, the composite materials that create microstructure and interconnection of pores highly influence the resistivity. The most common method for measuring surface concrete electrical resistivity is a non- destructive four point Wenner probe. To measure the resistivity, a current is applied to the two outer probes, and potential difference is applied between two inner probes as shown in Figure1. The resistivity is calculated based on the spacing of the probes as mentioned in Eq. 1.

$\rho=\frac{2 \pi a V}{I}$

Where, $\rho$ is the resistivity $(\Omega$-cm); $a$ is the distance between inner electrodes $(\mathrm{cm}) ; I$ is the alternating current supplied through outer probes $[A] ; V$ is the potential difference between inner probes $[V]$.

Table 1. Comparison of Electrical Resistivity and Corrosion Rate of Concrete [Broomfield, et al 1993]

\begin{tabular}{|l|l|}
\hline Corrosion Rate & $\begin{array}{l}\text { Concrete Electrical } \\
\text { Resistivity, } \boldsymbol{\rho ( k \Omega} \mathbf{-}-\mathbf{c m})\end{array}$ \\
\hline Low corrosion rate & $>100$ \\
\hline Low to moderate corrosion rate & $50-100$ \\
\hline High corrosion rate & $10-50$ \\
\hline Very high corrosion rate & $<10$ \\
\hline
\end{tabular}

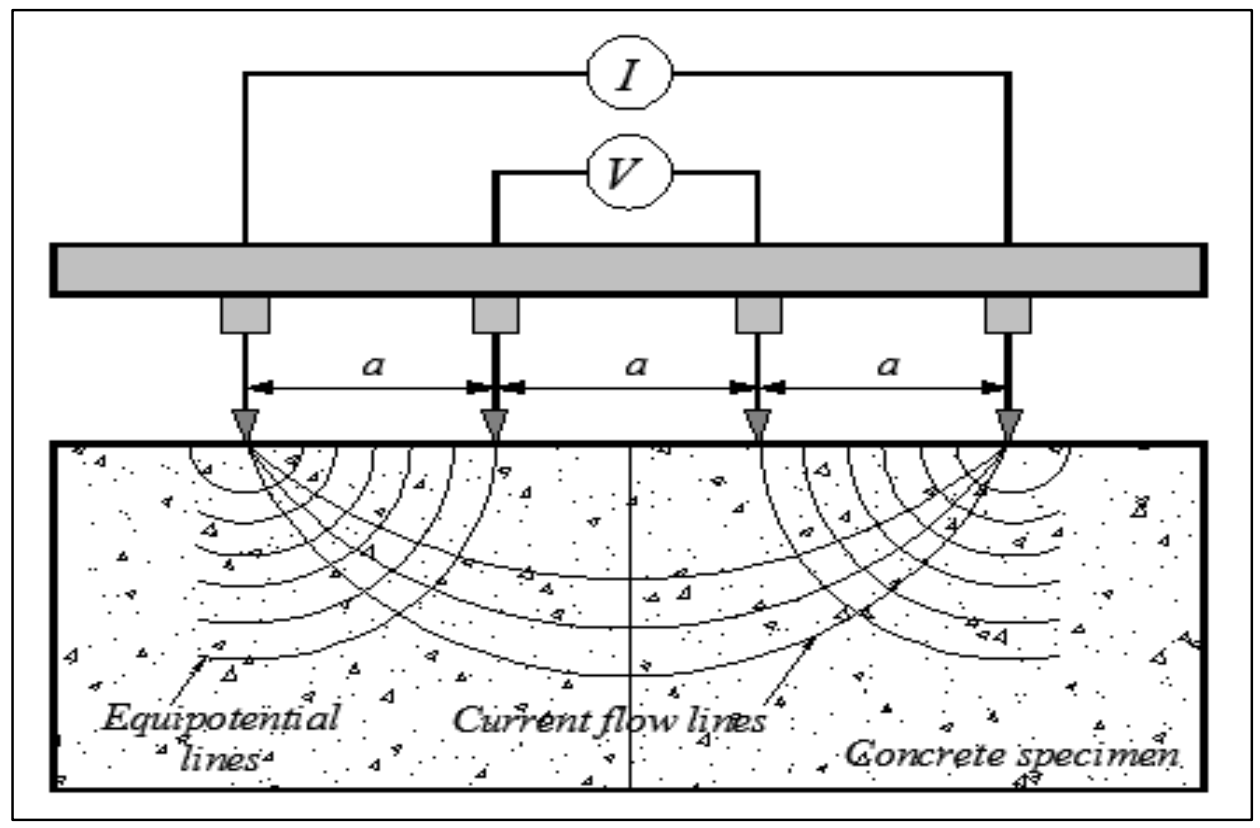

Figure 1. Schematic of four-electrode resistivity test 
Many researchers have been identified that the electrical resistivity as an indicator of chloride penetration resistance, for quality assurance and acceptance of concrete. Presently in the USA, concrete resistivity is substituted for the Rapid Chloride Penetrability Test for use as a quality control parameter through construction, to evaluate for concrete permeability [7]. Table 2 shows the comparison of chloride penetrability levels established for standards based on electrical resistivity [8]. The purpose of this paper is to introduce measurement of the electrical resistivity of concrete, to study factors such as w/b ratio, fly ash content, and cement paste content affecting the concrete electrical resistivity and find a relationship with other concrete properties, such as compressive strength and rapid chloride penetration.

Table 2. Comparison of Chloride Penetrability Levels Established for Standards Based on Electrical Resistivity (AASHTO TP95) and Charged Passed (ASTM C1202) [Whiting, 1981]

\begin{tabular}{|c|c|c|}
\hline \multicolumn{2}{|c|}{ ASTM C1202/ AASHTO T277 } & AASHTO TP95 \\
\hline $\begin{array}{l}\text { Chloride Ion } \\
\text { Penetrability }\end{array}$ & $\begin{array}{l}\text { RCP Test } \\
\text { Charged Passed } \\
\text { (Coulombs) }\end{array}$ & $\begin{array}{l}\text { Electrical Resistivity } \\
\text { Test (k } \Omega-c m)\end{array}$ \\
\hline High & $>4,000$ & $<12$ \\
\hline Moderate & $2,000-4,000$ & $12-21$ \\
\hline Low & $1,000-2,000$ & $21-37$ \\
\hline Very Low & $100-1,000$ & $37-254$ \\
\hline Negligible & $<100$ & $>254$ \\
\hline
\end{tabular}

\section{Experimental Program}

\section{Specimen Preparation}

In this research, electrical resistivity was measured for 20 different concrete mix proportions, as shown in Table 3. Dimensions of the tested specimens were $100 \times 100 \times 100 \mathrm{~mm}$ for cubic specimens and $\phi 100 \times 200 \mathrm{~mm}$ for cylindrical specimens. Three samples were cast for each mixture and shape. Ordinary Portland cement (type I) was used as a binder. Fly ash is also used to partially replace cement in concrete. Coal fly ash type 2b, according to TIS2135, from Mae-Moh power plant, was used as a cement replacement material at the levels of 0 , 10,30 , and $40 \%$ by weight. Water to binder ratios were $0.35,0.45,0.55$, and 0.65 respectively. Ratio of paste volume of concrete to void content between aggregate ( $\Upsilon$ ) was varied as 1.3 and 1.4. Void volume between aggregate can be determined based on ASTM C29 according to amount of fine and coarse aggregate used as shown in mix proportion. Natural river sand was used as a fine aggregate. Coarse aggregate, crushed limestone was used with a maximum size of $20 \mathrm{~mm}$. To obtain good workability of concrete at low w/b ratio, a superplasticizer (Mighty-X) was used. Two types of curing regimes used in this study were air curing and water curing. 
Table 3. Mix Proportions of the Tested Concrete

\begin{tabular}{|c|c|c|c|c|c|c|c|c|c|}
\hline \multirow{2}{*}{ No } & \multirow{2}{*}{ Designation } & \multirow{2}{*}{$\mathbf{w} / \mathbf{b}$} & \multirow{2}{*}{ r } & \multicolumn{6}{|c|}{ Unit Content $\left(\mathrm{kg} / \mathrm{m}^{3}\right)$} \\
\hline & & & & OPC & FA & Water & Sand & Gravel & SP \\
\hline 1 & $0.35 \mathrm{OPC}$ & 0.35 & 1.3 & 433 & 0 & 149 & 771 & 1138 & 2.16 \\
\hline 2 & 0.35 FA 10 & 0.35 & 1.3 & 385 & 43 & 148 & 771 & 1138 & 2.14 \\
\hline 3 & 0.35 FA 30 & 0.35 & 1.3 & 293 & 126 & 144 & 771 & 1138 & 2.93 \\
\hline 4 & 0.35 FA 40 & 0.35 & 1.3 & 248 & 166 & 143 & 771 & 1138 & 2.07 \\
\hline 5 & $0.45 \mathrm{OPC}$ & 0.45 & 1.3 & 377 & 0 & 168 & 771 & 1138 & 1.88 \\
\hline 6 & $0.55 \mathrm{OPC}$ & 0.55 & 1.3 & 333 & 0 & 183 & 771 & 1138 & 0 \\
\hline 7 & 0.55 FA 10 & 0.55 & 1.3 & 297 & 33 & 182 & 771 & 1138 & 0 \\
\hline 8 & 0.55 FA 30 & 0.55 & 1.3 & 227 & 97 & 179 & 771 & 1138 & 0 \\
\hline 9 & 0.55 FA 40 & 0.55 & 1.3 & 193 & 129 & 177 & 771 & 1138 & 0 \\
\hline 10 & $0.65 \mathrm{OPC}$ & 0.65 & 1.3 & 299 & 0 & 194 & 771 & 1138 & 0 \\
\hline 11 & $0.35 \mathrm{OPC}$ & 0.35 & 1.4 & 467 & 0 & 159 & 746 & 1101 & 4.67 \\
\hline 12 & 0.35 FA 10 & 0.35 & 1.4 & 416 & 46 & 159 & 746 & 1101 & 2.31 \\
\hline 13 & 0.35 FA 30 & 0.35 & 1.4 & 316 & 136 & 155 & 746 & 1101 & 3.16 \\
\hline 14 & 0.35 FA 40 & 0.35 & 1.4 & 268 & 179 & 154 & 746 & 1101 & 2.24 \\
\hline 15 & $0.45 \mathrm{OPC}$ & 0.45 & 1.4 & 407 & 0 & 181 & 746 & 1101 & 2.03 \\
\hline 16 & $0.55 \mathrm{OPC}$ & 0.55 & 1.4 & 360 & 0 & 198 & 746 & 1101 & 0 \\
\hline 17 & 0.55 FA 10 & 0.55 & 1.4 & 321 & 36 & 196 & 746 & 1101 & 0 \\
\hline 18 & 0.55 FA 30 & 0.55 & 1.4 & 245 & 105 & 193 & 746 & 1101 & 0 \\
\hline 19 & 0.55 FA 40 & 0.55 & 1.4 & 208 & 139 & 191 & 746 & 1101 & 0 \\
\hline 20 & $0.65 \mathrm{OPC}$ & 0.65 & 1.4 & 322 & 0 & 210 & 746 & 1101 & 0 \\
\hline
\end{tabular}

Remark: w/b is the water to binder ratio, $\Upsilon$ is volume ratio of paste content to void content between aggregate in concrete, OPC is ordinary Portland cement, FA is fly ash, and SP is superplasticizer. 


\section{Test Procedure}

\section{Electrical Resistivity of Concrete}

At 1 day after casting, specimen was demolded and cured in water. The four Wenner probe test, requiring wetting or saturating of the concrete before measurements, were was undertaken in the laboratory. In addition, the tips or probes of the electrode were also moistened in water to improve the electrical connection. The size of the probe is $3.81 \mathrm{~cm}$. Electrical resistivity was measured every four days from the age of 1 day to 28 days. After 28 days, measurements were taken every week until 91 days. After 91 days, specimens were kept in a room of which temperature and relative humidity is at $28 \pm 1^{\circ} \mathrm{C}$ and $70 \pm 5 \%$, respectively. Three concrete specimens were removed from the water and extra surface moisture were wiped off. When measuring all the points, the probes were made in contact with the concrete and waited for three to five seconds until stable readings were obtained. Average resistivity for the set of sample was then derived from the three specimens.

\section{Cubic Specimen Measurement on Electrical Resistivity of Concrete}

For each cubic specimen, resistivity measurement was performed on two opposite surfaces, while on each surface, two diagonal measurements perpendicular to each other were conducted. To get a good indication of concrete resistivity, five measurements were taken for their average. The measurement using the Wenner probe is shown in Figure 2 and 3.

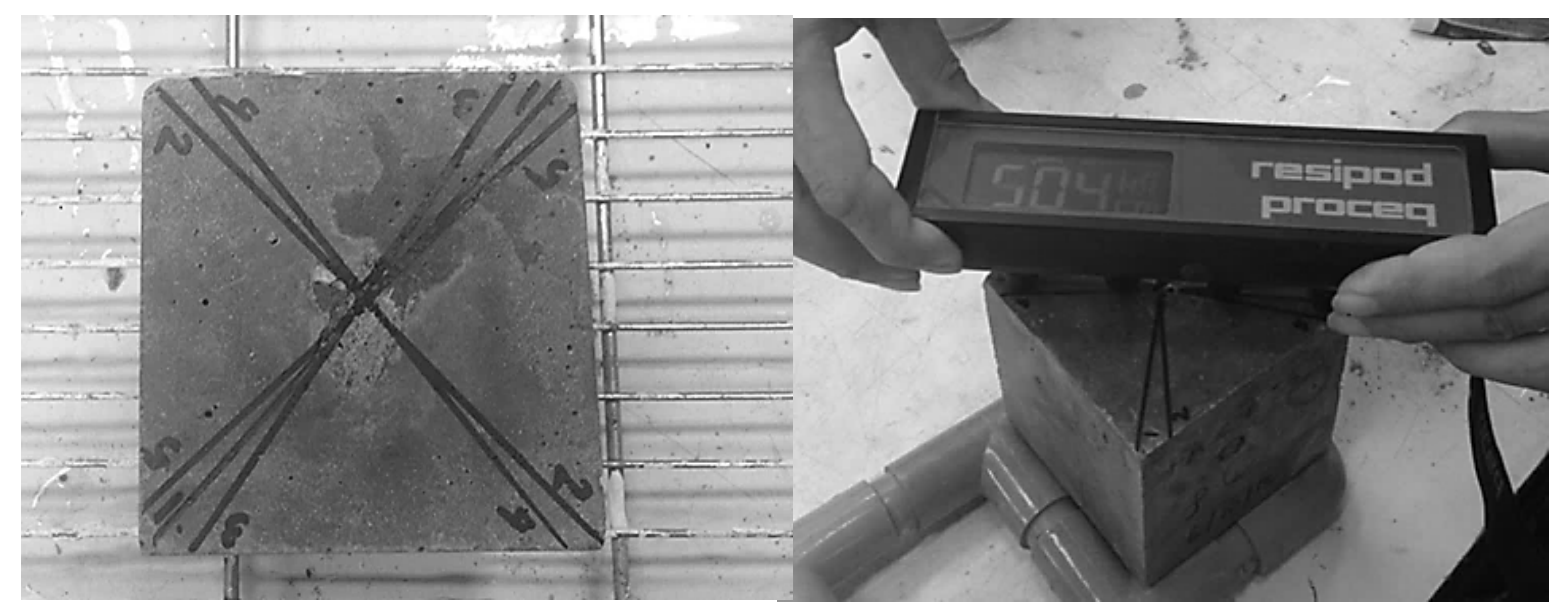

Figure 2. Cubic test specimen

Figure 3. Measurement technique for electrical resistivity of a cubic specimen using four Wenner probe

\section{Cylindrical Specimen Measurement on Electrical Resistivity of Concrete}

The test procedure was in accordance with AASHTO TP-95. Immediately after demolding, four permanent lines were drawn on the circumference face of the specimen marking 0,90 , 180, and 270 degree of the circular cross section. Then Wenner array probe was placed longitudinally on the specimen at the 0 degree line. The probe must be centered along the length of the concrete specimen [9]. Repetitions of the measurement were obtained at 90,180 and 270 degree lines as shown in Figure 4 and 5. 


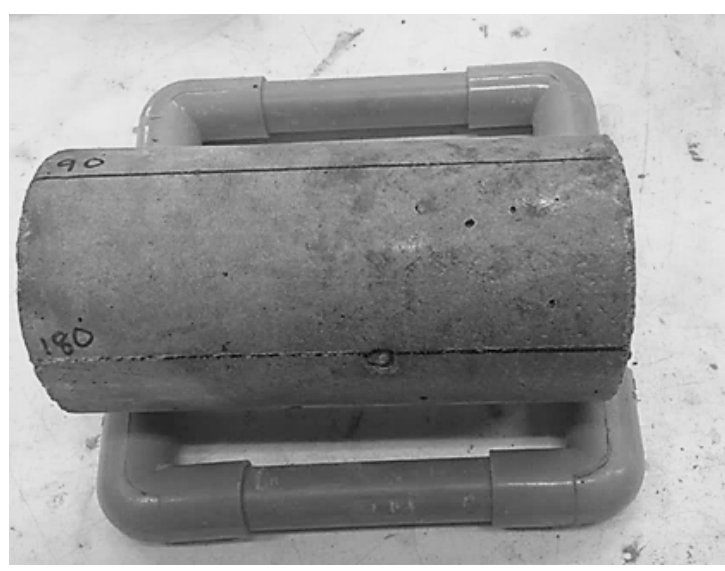

Figure. 4 Cylindrical test specimen

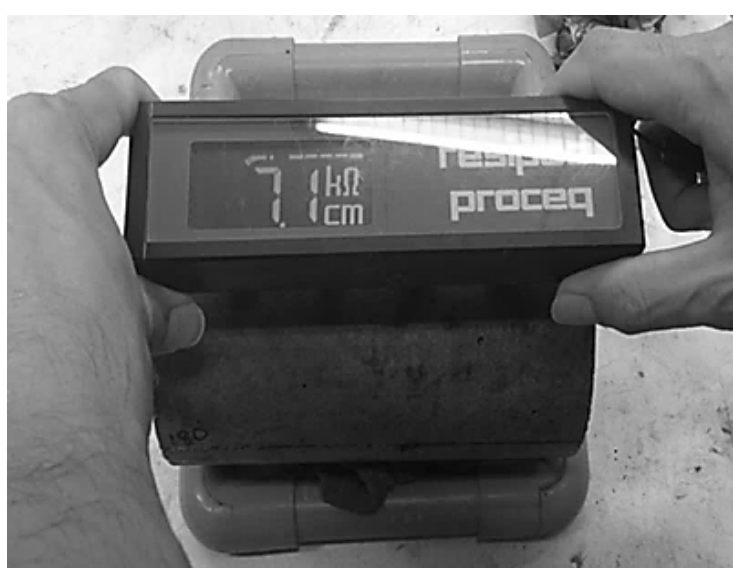

Figure. 5 Measurement technique for electrical resistivity of a cylindrical specimen using four Wenner probe

\section{Compressive Strength Test of Concrete}

The test procedure was in accordance with ASTM C39. Cubic specimens of (100 x $100 \mathrm{x}$ 100) $\mathrm{mm}$ concrete specimens were cast and demolded at 24 hours after casting. Specimens were cured in water and air conditions. The compressive strength tests were conducted at 7 , 14, 28, 56, and 91 days.

\section{Rapid Chloride Penetration Test of Concrete}

For rapid chloride penetration of water- saturated concrete, 100 x $200 \mathrm{~mm}$ cylindrical specimens were tested after 91 days of curing in accordance with ASTM C1202. Three 50$\mathrm{mm}$ disc samples were cut from a specimen and were placed in a vacuum for 3 hours. And, it was immersed in water and vacuum saturated for 1 hour and allowed to soak the water for 18 hours. Then each specimen was placed between two cells of $0.3 \mathrm{~N} \mathrm{NaOH}$ and $3 \% \mathrm{NaCl}$. The system was tested by applying potential difference of $60 \mathrm{~V}$ for 6 hours of direct current. After that samplewas removed from the cells, the current passed through the sample was calculated.

\section{Results and Discussion}

\section{Effect of mix proportion on electrical resistivity of concrete}

\section{Effect of $w / b$ Ratio}

As shown in Figure6, electrical resistivity increased with age of the concrete because of the densification due to cement hydration. According to the results, lower water to binder ratio concrete shows higher resistivity than those with higher water to binder ratios. This is because amount of interconnected pores decreases as the water/binder ratio decreases [10]. In long term, electrical resistivity still shows increasing trend even at the age of 270 days. 


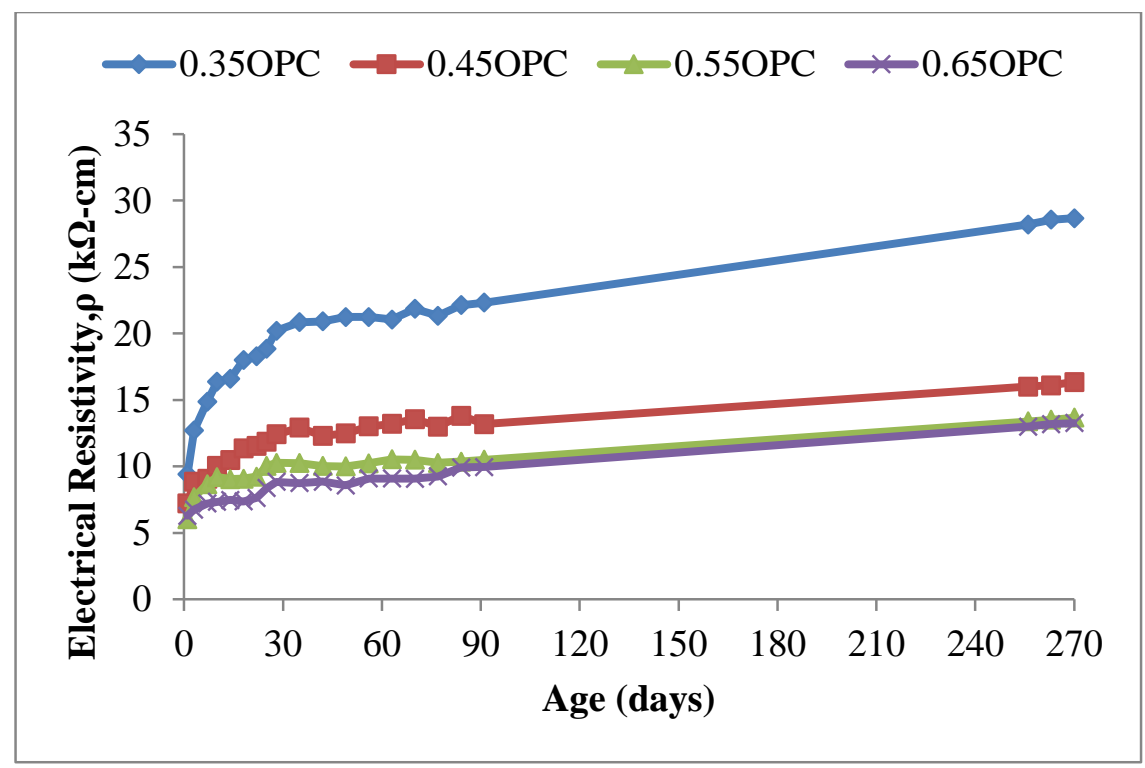

Figure 6. Effect of w/b ratio on electrical resistivity of concrete

\section{Effect of fly ash content}

Fly ash content has substantial influence on the concrete resistivity. Effect of fly ash on electrical resistivity is mainly related to the changes in the microstructure of concrete. The use of fly ash can reduce pore structure of concrete through its physical, and chemical effects both during the freshly mixed and subsequent hydrating states. The effects of changes in pore solution chemistry and refinement of pore structure on corrosion rate of $30 \%$ fly ash were also discussed [11]. Figure 7 and 8 illustrate the different fly ash replacement ratio with w/b ratio 0.35 and 0.55 , respectively. As shown in Figures, after 14 days electrical resistivity sharply increased, especially in case of concrete with $30 \%$ and $40 \%$ fly ash replacements. The rate of electrical resistivity increase with time is higher for fly ash concrete. Concrete with $10 \%$ fly ash replacement is not significantly different in term of resistivity from OPC. When $30 \%$ of fly ash is replaced, the concentration of hydroxyl ions is reduced, and pore distribution is finer than OPC concrete and electrical resistivity rate was obviously increased. And when cement is replaced at $40 \%$ by fly ash, electrical resistivity increased four times when compared to Ordinary Portland cement concrete. Fly ash causes finer pores and lower ionic concentration in the pores, that leads to higher electrical resistivity than OPC concrete [12]. In long term, resistivities of fly ash concrete show trends of more significant increase when compared to the OPC concrete. This is because of the pozzolanic reactivity of fly ash which is still active in long term. Therefore, corrosion current flow, in fly ash concrete is expected to be retarded. 


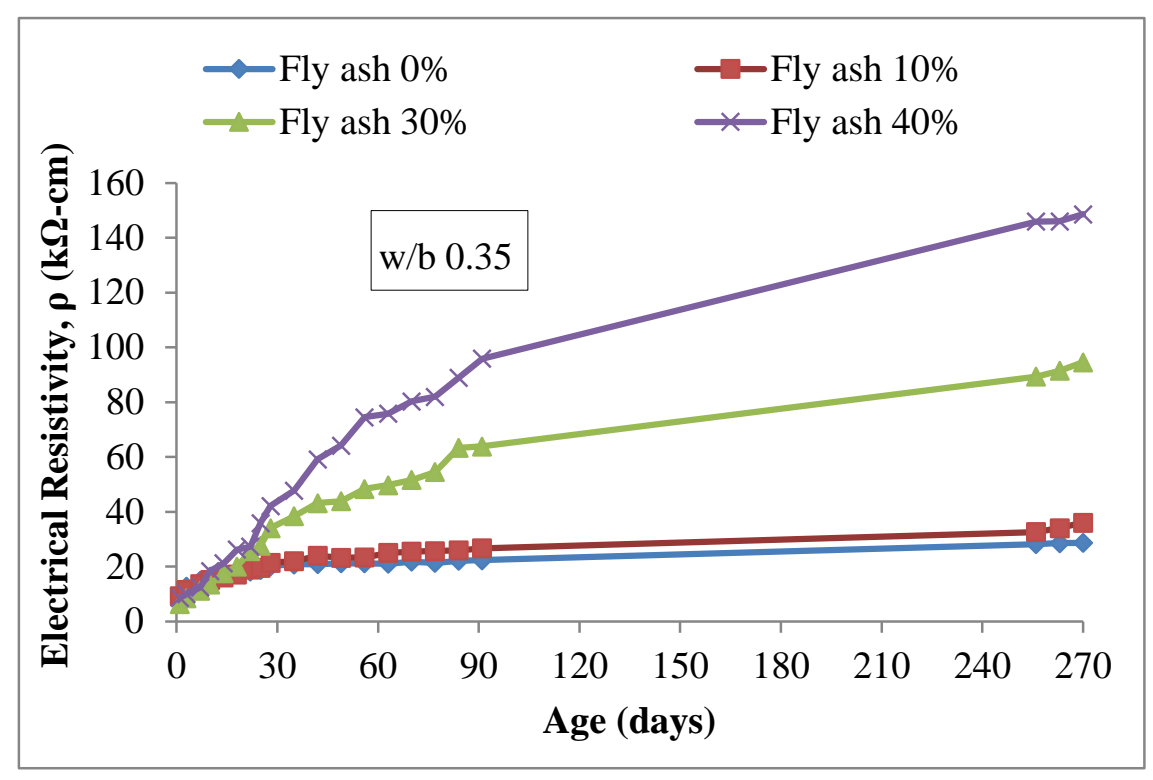

Figure 7. Effect of fly ash content with w/b 0.35 on the electrical resistivity of concrete

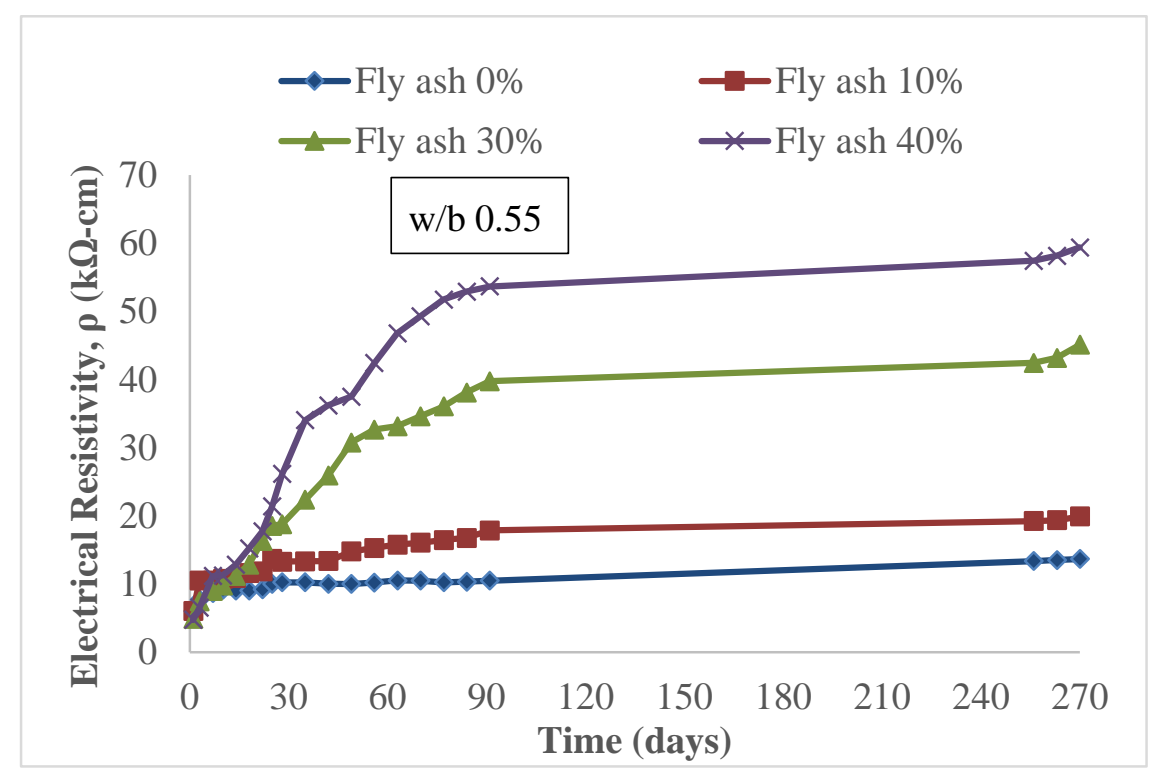

Figure. 8 Effect of fly ash content with w/b 0.55 on the electrical resistivity of concrete

Effect of ratio of paste volume to volume between aggregate $(Y)$

Low $(\Upsilon)$ concrete has higher resistivity than high $(\Upsilon)$ concrete because the larger amount of aggregate in lower content increases the electrical resistivity as shown in Figure 9. The aggregate electrical resistivity is higher than cement paste as shown in Table 4 [13]. At 91 days, the electrical resistivity of low paste content concrete was $15 \%$ higher than that of the high paste content concrete. Table 4 shows measured electrical resistivity of concrete materials. 


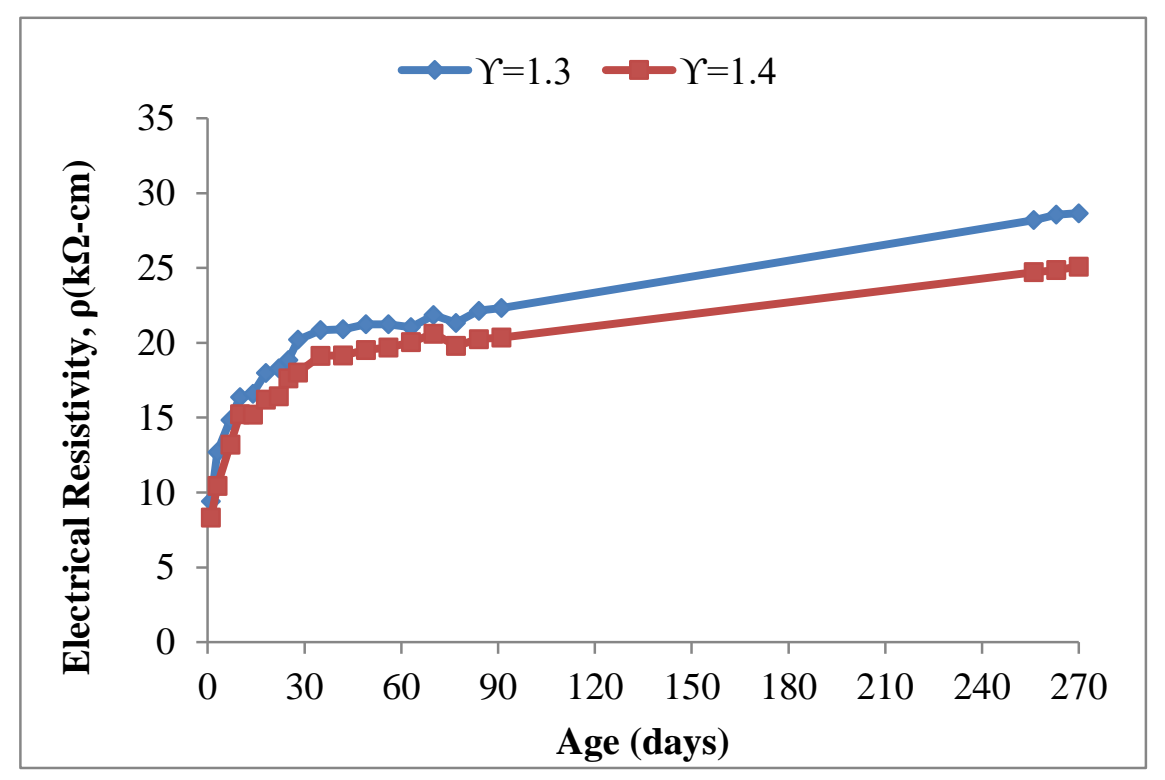

Figure 9. Effect of ratio of cement paste content of concrete to void between aggregate content on the electrical resistivity of concrete

Table. 4 Electrical Resistivity of Different Materials

\begin{tabular}{|l|l|}
\hline \multicolumn{1}{|c|}{ Materials } & \multicolumn{1}{|c|}{ Electrical Resistivity (k $\mathbf{\Omega - c m})$} \\
\hline Cement & $1 \times 10^{3}-4 \times 10^{3}[14]$ \\
\hline Cement paste & $1-1.3[15]$ \\
\hline Limestone aggregate & $5 \times 10^{3}-10^{8}[16]$ \\
\hline Sand & $5 \times 10^{2}-10^{4}[16]$ \\
\hline
\end{tabular}

\section{Relationship Between Concrete Properties and Electrical Resistivity}

\section{Relationship between Electrical Resistivity and Compressive Strength of Concrete}

The curing condition also plays an important role in the electrical resistivity, since the mobility of ions in the pores solution is largely affected. The electrical resistivity of concrete increased with age as a result of decreasing of pore space and increasing of hydration products. The concrete electrical resistivity highly depends on moisture content. Increasing of moisture content will result in decreasing in electrical resistivity. High compressive strength of concrete is due to increase of cement hydration that supports the growth of (C-S$\mathrm{H})$ gels. For hydration to proceed, $(\mathrm{C}-\mathrm{S}-\mathrm{H})$ gels must be saturated with water. Therefore, compressive strength of water cuing is higher than air- cured. Concrete with higher w/b ratio has lower strength and electrical resistivity due to larger amount of saturated capillary pores in the paste. The larger quantity of capillary pores results in lower density and lower strength of the paste. For fly ash concrete, strength at early ages is generally lower than that of the 
cement only concrete but higher in long term. Therefore, the relation with age in fly ash concrete is different from that of the OPC concrete. Despite, there is a good correlation of electrical resistivity and compressive strength of concrete in water- cured as shown in Figure 10. Based on the results as shown in Figure 11, air cured specimen showed higher electrical resistivity than that of water-cured specimen, even strength was lower at the same testing age. This is because water curing resistivity will increase due to cement hydration and pores filling with hydration products, though electrical resistivity of air curing will increase by losing of moisture from the concrete. As shown in Figure 11, correlation between electrical resistivity and compressive strength is lower than that of water- crued. This may due to difficulties to measure electrical resistivity of dry specimen. Moisture need to provide before measuring the electrical resistivity.

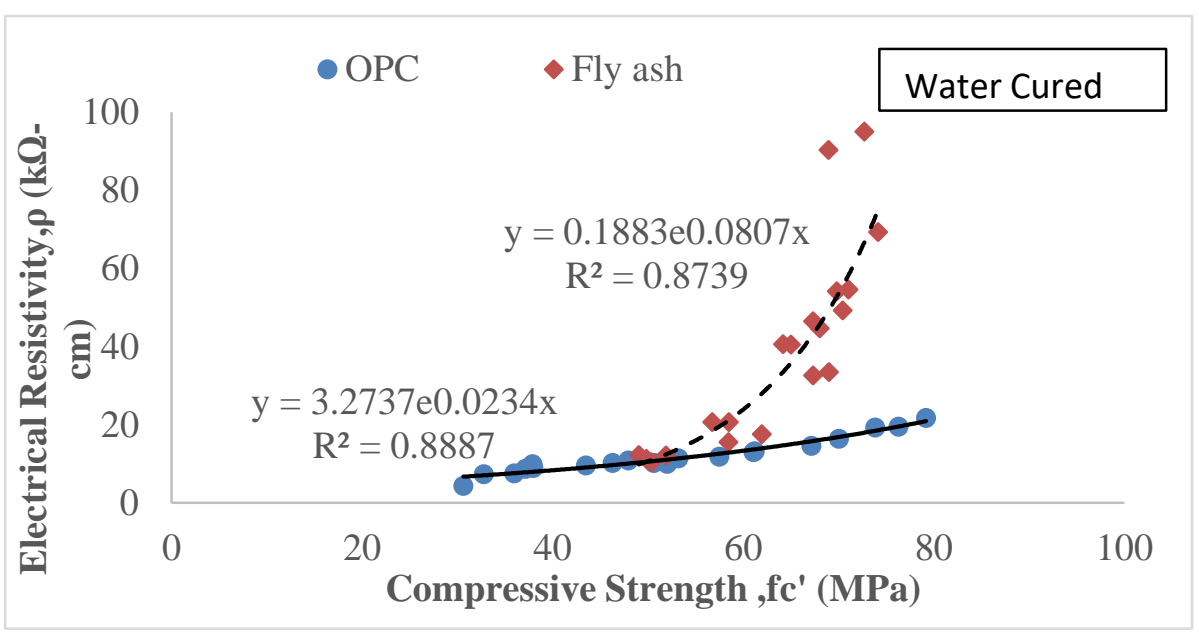

Figure 10. Relationship between compressive strength and electrical resistivity of concrete in water cured

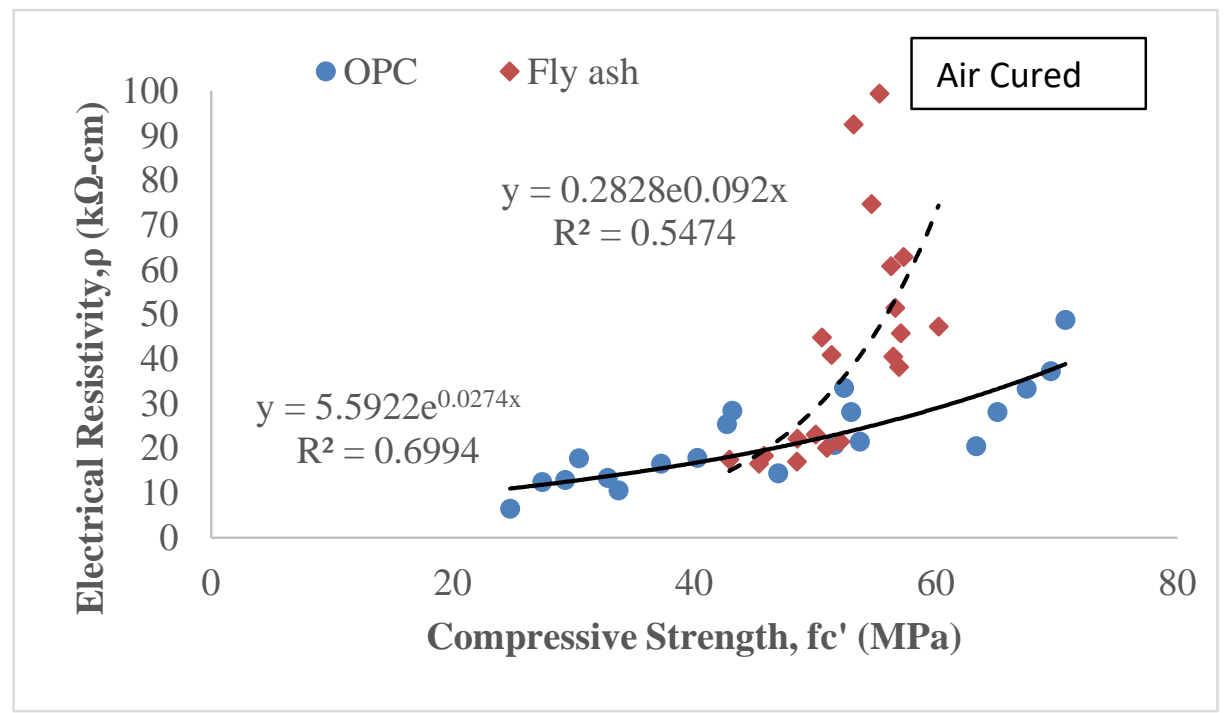

Figure 11. Relationship between Compressive Strength and Electrical Resistivity of Concrete in Air Cured 


\section{Relationship Between Electrical Resistivity and Rapid Chloride Penetration (RCPT) of Concrete}

Lower $\mathrm{w} / \mathrm{b}$ ratio increases resistance to chloride penetration due to decrease in volume pores of concrete resulting in impermeable concrete and increased in electrical resistivity. Increasing w/b ratios lead to a decrease in electrical resistivity and amount of charge passed, indicating a more permeable concrete. As the percentage of fly ash replacement ratio is increased, the electrical resistivity also increased. This indicates that concrete became more impermeable, less porous, denser microstructure. A discontinuous pore system creates also reduced chloride ion permeability.. Lower cement paste content shows higher electrical resistivity and lower rapid chloride penetration because of increasing aggregate content. The relationship between electrical resistivity and rapid chloride penetration obtained from all concrete mixes in this study compared to Rupnow and Icenogle [17] is shown in Figure12.The correlation between the two test results is $\mathrm{R}^{2}$ of 0.9851 .

When electrical resistivity increased, charge passed significantly reduced. Charge passed is mainly controlled by pore structure, similar to electrical resistivity. Both of w/b ratio reduction and fly ash replacement can be considered a refinement of pore structure. Electrical resistivity test is easy to use, fast and repeatable to test, and a strong correlation with rapid chloride permeability can be obtained. Table. 5 shows the relationship between electrical resistivity and rapid chloride penetration of concrete obtained by Rupnow and Icenogle and this study. Results showed that other results underestimate RCPT of concrete in Thailand. Therefore, the effect of local materials properties should be considered.

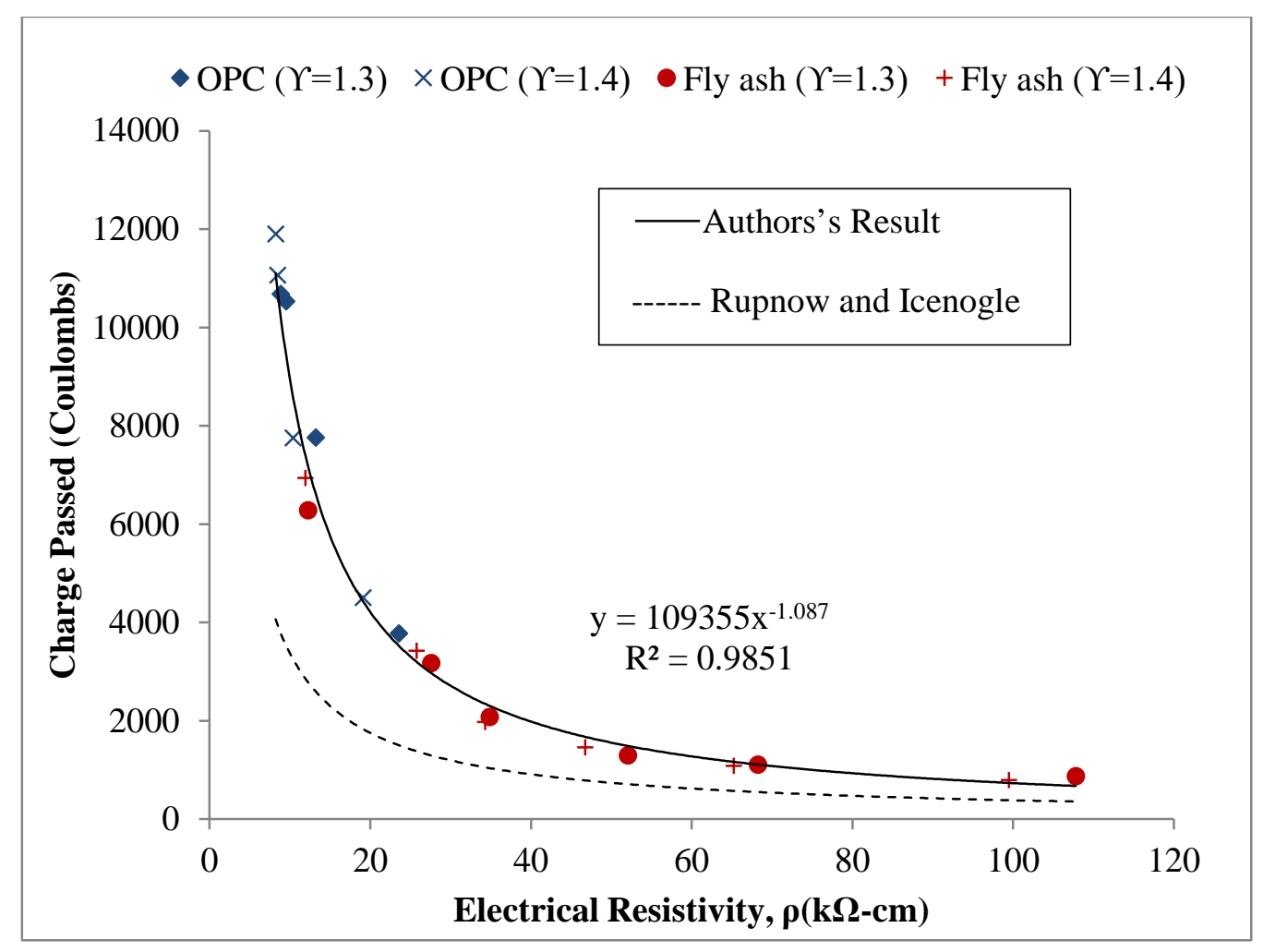

Figure 12. Relationship between rapid chloride penetration and electrical resistivity of all concrete mixes 
Table 5. Relationship Between Electrical Resistivity and Rapid Chloride Penetration of Concrete

\begin{tabular}{|c|c|c|c|c|}
\hline \multicolumn{2}{|c|}{ ASTM C1202/ AASHTO T277 } & \multirow{2}{*}{$\begin{array}{l}\text { AASHTO } \\
\text { TP95 } \\
\text { Electrical } \\
\text { Resistivity } \\
\text { Test (k } \Omega-c m)\end{array}$} & \multirow{2}{*}{$\begin{array}{l}\begin{array}{l}\text { Rupnow and } \\
\text { Icenogle }\end{array} \\
\text { Electrical } \\
\text { Resistivity } \\
\text { Test (k } \Omega-c m)\end{array}$} & \multirow{2}{*}{$\begin{array}{l}\begin{array}{l}\text { Author's } \\
\text { Result }\end{array} \\
\text { Electrical } \\
\text { Resistivity } \\
\text { Test (k } \Omega-c m)\end{array}$} \\
\hline & $\begin{array}{l}\text { RCP Test } \\
\text { Charge Passed } \\
\text { (coulombs) }\end{array}$ & & & \\
\hline High & $>4,000$ & $<12$ & - & $<25$ \\
\hline Moderate & $2,000-4,000$ & $12-21$ & $10-25$ & $25-45$ \\
\hline Low & $1,000-2,000$ & $21-37$ & $25-40$ & $45-65$ \\
\hline Very Low & $100-1,000$ & $37-254$ & $40-80$ & $65-100$ \\
\hline Negligible & $<100$ & $>254$ & - & - \\
\hline
\end{tabular}

\section{Conclusions}

Based on experimental results, good relationship was obtained between results of compressive strength and rapid chloride penetration with electrical resistivity of concrete. The results of this study can be applied further to predict electrical resistivity of concrete when mix proportions are provided. According to results, lower water/binder ratio had higher resistivity than those with higher water/binder ratio. When cement was replaced by fly ash higher than 30\%, electrical resistivity was increased significantly Moreover, lower paste volume increased electrical resistivity due to higher aggregate content.

\section{Acknowledgements}

Authors would like to acknowledge AUN/Seed-Net and SIIT for supporting a scholarship to study at Sirindhorn International Institute of Technology. And authors acknowledge the Center of Excellence in Material Science, Construction and Maintenance Technology Project, Thammasat University and the National Research University Project, Office of the Higher Education Commission.

\section{References}

[1] C. Alonso, C. Andrade, and J.A. Gonzales, "Relation between resistivity and corrosion rate of reinforcement in carbonated mortar made with several cement types," Cement and Concrete Research, Vol. 18, pp. 687-698, 1988.

[2] J.P. Broomfield, Corrosion of Steel in Concrete: Understanding, Investigation and Repair, $2^{\text {nd }}$ Edition, Taylor and Francis, United Kingdom, 2007.

[3] B.J. Silva, S. Jalali, and R.M. Ferreira, Estimating electrical resistivity based on early age measurements, $1^{\text {st }}$ Edition, RILEM, Madrid, 2007.

[4] C. Andrade, The limit of service life of concrete structures, Spain, pp. 1-25, 2004. 
[5] J.P. Broomfield, Corrosion of Steel in Concrete: Understanding, Investigation and Repair, $1^{\text {st }}$ Edition, E \& FN Spon, United Kingdom, 1997.

[6] A. Mahasiripan, P. Sancharoen, and S. Tangtermsirikul, "A study of different sacrificial anode materials to protect corrosion of reinforcing steel in concrete," Thammasat International of Science and Technology, Vol. 19, No. 4, 2014.

[7] R. Kessler, R.G. Powers, E. Vivas, M.A. Paredes, and Y.P. Virmani, "Surface Resistivity as an Indicator of Concrete Chloride Penetration Resistance,” In: 2008 Concrete Bridge Conference, Portland Cement Association, Florida, pp. 1-18, 2008.

[8] D. Whiting, Rapid Determination of the Chloride Permeability of Concrete, Report No. FHWA/RD - 81/119, Federal Highway Administration, Washington, D.C., p. 174, 1981.

[9] Florida Method of Test for Concrete Resistivity as an Electrical Indicator of its Permeability, Designation: FM 5- 578, Florida Department of Transportation, 2004.

[10] K. Hornbostel, C.K. Larsen, and M.R. Geiker, "Relationship between concrete resistivity and corrosion rate: A literature review," Cement \& Concrete Composites, Vol. 39, pp. 60-72, 2013.

[11] S. Ehtesham, and H. Rasheeduzzafar, "Corrosion resistance performance of fly ash blended cement concrete,” ACI Materials Journal, Vol. 91, No. 3, pp. 264-271, 1994.

[12] D. Whiting, A. Todres, M. Nagi, T. Yu, D. Peshkin, M. Darter, J. Holm, M. Andersen, and M. Geiker, Synthesis of Current and Projected Concrete Highway Technology, SHRP-C-345, Strategic Highway Research Program, National Research Council, Washington, D.C., United States of America, 1993.

[13] G.E. Monfore, "The electrical resistivity of concrete," Journal of the PCA Research and Development Laboratories, Vol. 10, No. 2, pp. 35-48, 1968.

[14] G.A Woelfl, and K. Lauer, "The electrical resistivity of concrete with emphasis on the use of electrical resistance for measuring moisture content," Cement Concrete and Aggregates, Vol. 1 pp. 64-67.

[15] G.P. Gu, J.J. Beaudoin, and V.S. Ramachandran, “Techniques for corrosion investiga-tion in reinforced concrete,” In Handbook of Analytical Techniques in Concrete Science and Technology, V.S. Ramachandran, and J.J. Beaudoin, eds: William Andrew Publishing, New York, p. 456, 2001.

[16] J.M. Reynolds, An Introduction to Applied and Environmental Geophysics, Wiley, New York, p. 796, 1997.

[17] T.D. Rpunow, and P.J. Icenogle, Evaluation of Surface Resistivity Measurements as an Alternative to the Rapid Chloride Permeability Test for Quality Assurance and Acceptance, FHWA/LA. 13/496, Louisiana Transportation Research Center, Baton Rouge, Louisiana, United States of America, 2012. 